\title{
CT SCAN DIAGNOSIS OF LYMPHOMA IN PRETREATMENT CALCIFIED LYMPHADENOPATHY WITH ITS CLINICAL AND HISTOPATHOLOGY CORRELATION
}

Patil Saurabh S1, Shah Vaibhav R², Choudhary Vivek A ${ }^{3}$

\section{HOW TO CITE THIS ARTICLE:}

Patil Saurabh S, Shah Vaibhav R, Choudhary Vivek A. "CT Scan Diagnosis of Lymphoma in Pretreatment Calcified Lymphadenopathy with its Clinical and Histopathology Correlation". Journal of Evolution of Medical and Dental Sciences 2014; Vol. 3, Issue 11, March 17; Page: 2727-2731, DOI: 10.14260/jemds/2014/2200

ABSTRACT: Lymphoma commonly presents as Lymphadenopathy of multiple groups along with hepatosplenomegaly in most of the patients. Pretreatment calcification in the affected nodes is very rare whereas calcifications in nodes following radiation or chemotherapy have been documented in many cases. Imaging plays a pivotal role in prompting the clinician to suspect lymphoma and opt for biopsy. Especially in Indian setup where a large group of population with calcified Lymphadenopathy is many a times simply labeled as tuberculosis. It is well observed that post treatment calcification in lymphoma is associated with favorable prognosis while the available limited literature states that pretreatment calcification indicates aggressive disease. In this case report we present a case of pretreatment calcification in lymphoma diagnosed by CT scan along with its clinical and histopathological profile.

KEYWORDS: CT, Lymphoma, Calcification, Lymph node.

INTRODUCTION: The causes of abdominal lymphadenopathy are many and include the entire spectrum of neoplastic, inflammatory and infectious processes. Lymphoma is the most common malignancy manifesting as mesenteric Lymphadenopathy. ${ }^{1}$ However calcification in the lymphomatous nodes is very rare and occurs in less than $1 \%$ of the cases. ${ }^{2}$ In the context of developing countries the most common cause of calcified mesenteric lymph nodes is previous chronic granulomatous infection especially Tuberculosis. ${ }^{3}$ CT scan is useful for identifying the deep seated lymph nodes and speculates about their benign or malignant etiology and thus direct further management. We report a rare case of 60 year old male patient with calcified lymphadenopathy in whom Lymphoma was detected on CT scan and confirmed by histopathology examination.

CASE REPORT: A 60 year old male presented with the complaints of lump in abdomen with dull aching pain, mild fever, and sudden onset weight loss without any obvious bowel complaints. Per abdominal examination revealed a mobile lumpy mass in the central abdomen. On general examination, no obvious palpable lymphadenopathy was seen. The treating surgeon advised ultrasound of the abdomen which revealed a clumped mass of enlarged lymph nodes in the abdomen many of them giving extensive posterior acoustic shadowing suggestive of presence of calcification.

There was mild hepatosplenomegaly but no evidence of ascites or altered morphology of the bowel coils. He was referred for a contrast enhanced CT scan of the abdomen that revealed multiple enlarged, lymph nodes in the mesentery, preaortic, Para aortic and precaval regions. Some of them were forming conglomerate masses measuring upto $5.2 \times 3.4 \mathrm{~cm}$ and causing displacement of the adjacent vessels and bowel loops (Figure 1). However no obvious encasement of the aorta or IVC was seen. Many of these nodes had amorphous calcification in them and few of them were calcified at the 
periphery. On intravenous contrast scan, the enlarged nodes had a homogenous pattern of enhancement (Figure.2). The finding of mild hepatosplenomegaly was confirmed however the solid organs or bowel coils did not show any focal lesion in them (Figure 3).

The homogenous enhancement, conglomerate mass formation with displacement of adjacent vessels and bowel coils by the enlarged lymph nodes along with hepatosplenomegaly favored lymphomatous etiology. Though the calcification of nodes in absence of any prior treatment indicated possibility of underlying chronic granulomatous etiology like TB but the absence of ascites or bowel involvement with no obvious history of TB contact ruled out the possibility of the same. These imaging findings along with the clinical history made a strong case for malignancy and the diagnosis we put up was of lymphoma.

The patient was posted for an excisional biopsy. Pre-operative blood work was normal and the serum calcium levels were also within normal limits. The excised lymph node was sent for histopathology examination where on microscopy there was loss of the normal nodal architecture and the entire node was filled with monotonous population of lymphoid cells. No Reed Sternburg cells were seen. The final diagnosis given was of Non-Hodgkin's Lymphoma.

DISCUSSION: Lymphoma is the commonest malignancy manifesting as mesenteric lymphadenopathy. ${ }^{1}$ The other sites that can be involved are mediastinum, retroperitoneum or the superficial lymph node groups like cervical, inguinal etc. The affected lymph node groups if seen in the early stage of disease are mainly seen as multiple small discrete lesions. However in the later stage they coalesce to form a soft tissue mass. These masses generally grow around and displace adjacent structures. ${ }^{4}$

Calcification whenever identified in the lymphomatous nodes on radio imaging is nearly always as result of previous treatment. It is usually seen in post radiotherapy and has prevalence of $8 \% .{ }^{5}$ However in few instances calcification is also seen secondary to chemotherapy. ${ }^{6}$ The various patterns of calcification encountered are clustered, multiple, punctuate, amorphous or peripheral. ${ }^{2}$

The mechanism of calcification in affected nodes of lymphoma is uncertain but hypercalcemia or infarction with dystrophic calcification is the postulated mechanisms. Some varieties of $\mathrm{T}$ cell lymphoma are known to alter the calcium metabolism and exert their action by producing a factor similar to osteoclast activating factor. ${ }^{7}$ There is also evidence of infarction to occur in nodes affected by non-Hodgkin's Lymphoma. ${ }^{8}$ Calcification in Lymphoma occurring before treatment is found commonly in mediastinum followed by abdomen. However irrespective of the site of involvement it is always associated with aggressive disease and poor prognosis. On the contrary post treatment calcification is observed to have good prognosis. ${ }^{8,9}$

Pathologically lymphomatous nodes are seen as rubbery masses with destruction of the nodal architecture. The normal lymphoid cells which are seen in different stages of development are replaced by uniform lymphoid cells with large nuclei. Presence of Reed Sternburg cells is seen in Hodgkin type while the absence of it is seen in Non Hodgkin type. Further characterization of the cell type like B cell or T cell etc. can be done using Immunohistochemistry. ${ }^{10}$

Ultrasound can identify the lymph nodes in most of the cases but it has got a low sensitivity as far as etiological classification of the nodes is considered. Contrast enhanced CT is a very useful modality especially for Hodgkin disease and can be used to find the enlarged nodes based on their anatomical sites. The involvement of the visceral organs can also be identified if present significantly, 
however it is not sensitive to identify micrometastasis. MRI is even better than CT scan and is the imaging modality of choice as far as cranial and spinal involvement of lymphoma is considered. The use of Gadolinium based contrast for studying dynamic contrast uptake patterns and newer techniques like ultra-small supraparamagnetic iron oxide particles which are taken up preferentially by the unaffected nodes has increased the sensitivity of this technique. Radionuclide and PET imaging have their share of false negatives and false positives however they are very useful when used in conjunction with CT or MRI to assess an equivocal node or to identify recurrence. ${ }^{11}$

Thus to conclude imaging has a definite role in evaluation of a pretreatment nodal calcification in Lymphoma.

Figure 1: Non contrast axial CT scan image of abdomen showing lymph nodal mass in pre and para aortic regions with amorphous dense as well as rim calcification.

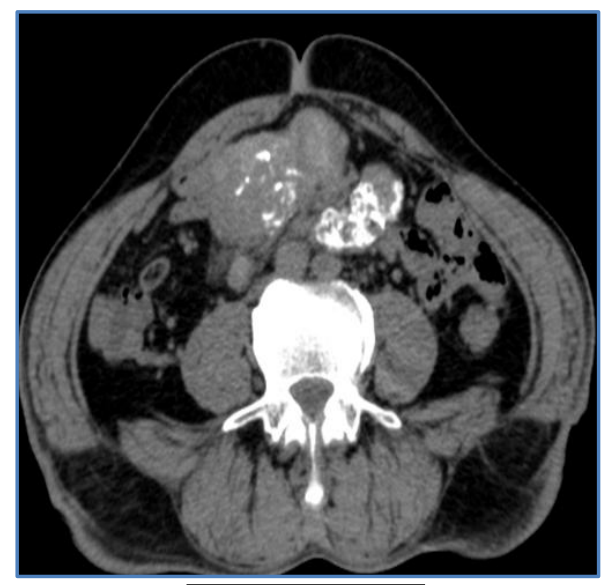

Figure 1

Figure 2: Contrast enhanced axial CT scan image of abdomen showing the calcified nodal mass to be mildly and homogenously enhancing and causing displacement of adjacent bowel coils.

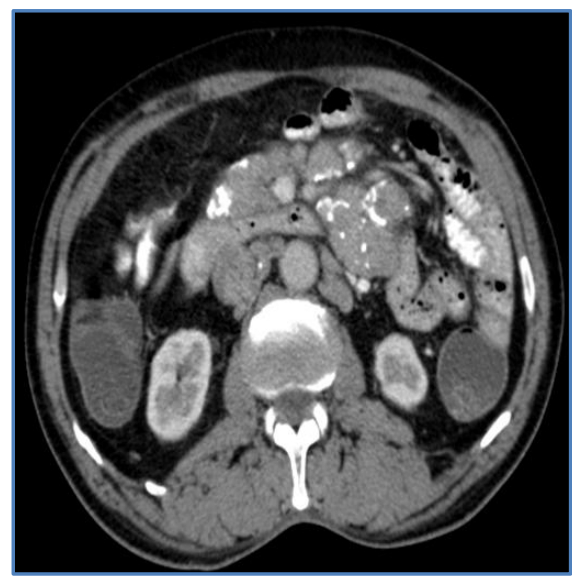

Figure 2 
Figure 3: Coronal reformatted CECT image shows hepatomegaly with no other focal bowel mass lesion.

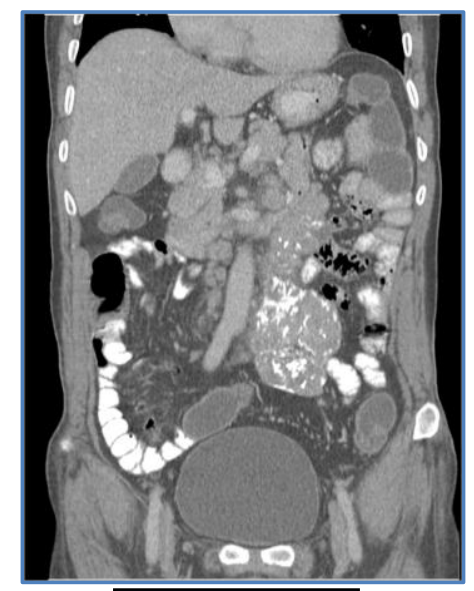

Figure 3

\section{BIBLIOGRAPHY:}

1. Cole SM. Computed tomography of lymphomatous involvement of mesenteric nodes. Radiography 1986; 52:299-301.

2. Apter S, Avigdor A, Gayer G, Portnoy O, Zissin R, Hertx M. Calcification in Lymphoma occurring before therapy: CT features and clinical correlation. AJR. 2202 April; 178: 935-38.

3. Khan M Q, Al-Qahtani AQ, Al-Momen S, Aldhurais SA, Ahmad M. Widespread tuberculous calcification. Saudi Medical Journal. 2000; 21(4):386-89.

4. Lucey B C, Stuhlfaut JW, Soto JA. Mesenteric lymph nodes seen at imaging: Causes and significance. Radiographics 2005; 25: 351-365.

5. Rivero H, Gaisie G, Bender TM, Sang-Oh K. Calcified mediastinal lymph nodes in Hodgkin's Disease. Pediatr Radiol. 1984; 14: 11-13.

6. Bertrand $\mathrm{M}$, Chen J, Libshitz $\mathrm{H}$. Lymph node calcification in Hodgkin Disease after chemotherapy. AJR 1997; 129: 1108-1110.

7. Grossman B, Schectar GP, Hoston J E, Pierce L, Jaffe ES, Wahl L. Hypercalcemia associated with T-cell lymphoma-leukemia. Am J CLin Pathol. 1981; 75:149-155.

8. Cleary K R, Osborne BM, Butler J J. Lymph node infarction foreshadowing malignant lymphoma. Am J Surg Pathol. 1982; 6: 435-442.

9. Strijk S P. Lymph node calcification in malignant lymphoma: Presentation of nine cases and review of the literature. Acta Radiol Diagn 1985; 26:427-43.

10. Kumar V, Abbas AK, Fausto N, Aster JC eds. Robbins \& Cotran Pathologic Basis of Disease. $8^{\text {th }}$ ed. Philadelphia: Saunders Elsevier Publications; 2010.

11. Cherryman GR, Morgan B. The lymphatic system. In: Sutton D, editor. Textbook of Radiology and Imaging. $7^{\text {th }}$ edition. Kundli: Elsevier Churchill Livingstone; 2002. 


\section{CASE REPORT}

\section{AUTHORS:}

1. Patil Saurabh S.

2. Shah Vaibhav R.

3. Choudhary Vivek A.

\section{PARTICULARS OF CONTRIBUTORS:}

1. Resident Doctor, Department of Radiology, Dr. V. M. Government Medical College \& SCSM, General Hospital, Solapur, Maharashtra.

2. Assistant Professor, Department of Radiology, Dr. V. M. Government Medical College \& SCSM, General Hospital, Solapur, Maharashtra.

3. Professor and HOD, Department of Radiology, Dr. V. M. Government Medical College \& SCSM, General Hospital, Solapur, Maharashtra.

\section{NAME ADDRESS EMAIL ID OF THE} CORRESPONDING AUTHOR:

Dr. Patil Saurabh S,

Room No. 37, Resident Doctor Hostel, Civil Hospital Campus,

Solapur - 413003, Maharashtra.

E-mail: psaurabh12000@gmail.com

Date of Submission: 13/02/2014. Date of Peer Review: 14/02/2014. Date of Acceptance: 22/02/2014.

Date of Publishing: 11/03/2014. 